\title{
Aortic valve replacement in low-flow, low-gradient aortic stenosis: Left ventricular ejection fraction matters
}

\author{
Victor Dayan, $\mathrm{MD}, \mathrm{PhD},{ }^{\mathrm{a}}$ and Philippe Pibarot, $\mathrm{DVM}, \mathrm{PhD}^{\mathrm{b}}$
}

\footnotetext{
From the ${ }^{\mathrm{a}}$ Centro Cardiovascular Universitario, Hospital de Clinicas, Facultad de Medicina, Universidad de la Republica, Montevideo, Uruguay; and the ${ }^{\mathrm{b}}$ Institut Universitaire de Cardiologie et de Pneumologie de Québec (Québec Heart and Lung Institute), Laval University, Québec City, Québec, Canada.

Disclosures: Authors have nothing to disclose with regard to commercial support.

Received for publication March 21, 2017; accepted for publication March 23, 2017; available ahead of print April $18,2017$.

Address for reprints: Victor Dayan, MD, PhD, 26 de Marzo 3459/602, Montevideo, Uruguay (E-mail: victor_dayan@hotmail.com).

J Thorac Cardiovasc Surg 2017;154:443-4

$0022-5223 / \$ 36.00$

Copyright $(2017$ by The American Association for Thoracic Surgery

http://dx.doi.org/10.1016/j.jtcvs.2017.03.102
}

Patients with severe aortic stenosis (AS) and symptoms or depressed left ventricular ejection fraction (LVEF) have a dismal prognosis on conservative management. Aortic valve replacement (AVR) is thus associated with a major survival benefit in these patients. AS is a complex and heterogeneous entity, however, and it harbors several different flow and gradient patterns. There is a general consensus that patients with "high-gradient" AS (mean gradient $\geq 40 \mathrm{~mm} \mathrm{Hg}$ ) have hemodynamically severe AS and thus a class I indication for AVR if the patient has symptoms or LVEF less than $50 \%{ }^{1}$ The therapeutic management is more complex and debated for patients with a "low-gradient" pattern, however, which is defined as an aortic valve area less than $1.0 \mathrm{~cm}^{2}$ and indexed aortic valve area less than $0.6 \mathrm{~cm}^{2} / \mathrm{m}^{2}$ but a low gradient $(<40 \mathrm{~mm} \mathrm{Hg}$ ). Given that the gradient is highly flow dependent, the main cause of low-gradient AS is the presence of a low-flow state (stroke volume index $<35 \mathrm{~mL} / \mathrm{m}^{2}$ ). The low-flow, low-gradient (LFLG) entity includes 2 main sub-categories, depending on the LVEF: (1) classic LFLG, in which the low-flow state is mainly related to depressed left ventricular systolic function (LVEF $<50 \%$ ), and (2) paradoxic LFLG (PLFLG), which is characterized by a preserved LVEF but nonetheless a low flow related to pronounced left ventricular concentric remodeling, advanced diastolic dysfunction, and other factors, including atrial fibrillation, and concomitant mitral regurgitation or stenosis.

In this issue of the Journal, Lopez-Marco and colleagues ${ }^{2}$ compare for the first time the outcomes after AVR of patients with PLFLG AS and classic low-gradient AS. In their study, Lopez-Marco and colleagues ${ }^{2}$ show that classic LFLG AS is associated with worse outcomes after AVR relative to PLFLG AS, which is consistent with previous studies. On the other hand, several studies ${ }^{3}$ have also reported that the outcomes are even much worse with conservative management, and AVR therefore remains the best option for patients with classic LFLG AS. The benefit of AVR is more uncertain and controversial for the subset of patients with PLFLG AS.

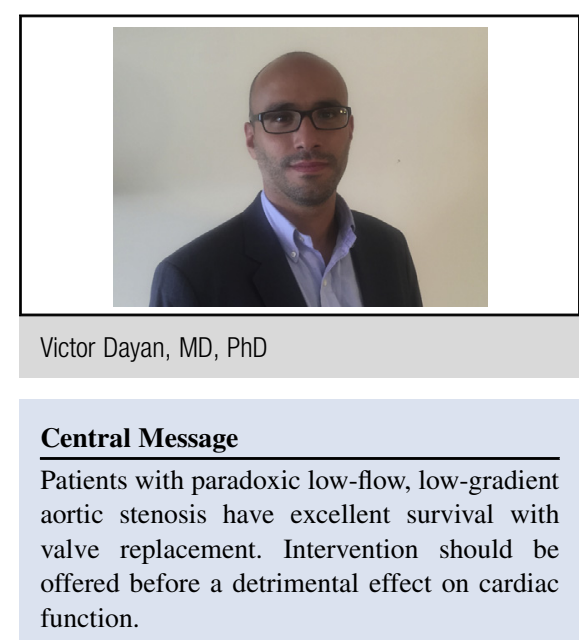

See Article page 435 .

Although a recent meta-analysis concluded that patients with PLFLG AS do benefit from AVR, other studies have suggested that this entity is rather a moderate form of AS and found no survival gain with AVR. ${ }^{4}$

The main findings of the study presented by Lopez-Marco and colleagues ${ }^{2}$ is that the survivals of patients with PLFLG, who represented one-third of their cohort, were as good as those of patients with high-gradient AS. On the other hand, patients with classic LFLG AS had worse outcomes than did those with PLFLG AS, reemphasizing the negative impact of low LVEF on outcomes after surgical AVR. The findings of this study thus provide further support and greater evidence to the class IIa indication of AVR proposed in the guidelines for patients with severe, symptomatic PLFLG AS. They also emphasize the need for improving the therapeutic management of patients with classic LFLG. To this effect, further studies are needed to determine whether earlier or transcatheter AVR would improve outcomes for these high-risk patients with low LVEF and low gradient.

\section{References}

1. Nishimura RA, Otto CM, Bonow RO, Carabello BA, Erwin JP III, Guyton RA, et al American College of Cardiology/American Heart Association Task Force on Practice Guidelines. 2014 AHA/ACC guideline for the management of patients with valvular heart disease: a report of the American College of Cardiology/American Heart Association Task Force on Practice Guidelines. J Am Coll Cardiol. 2014; 63:e57-185. Erratum in: J Am Coll Cardiol. 2014;63:2489.

2. Lopez-Marco A, Miller H, Kumar P, Ashraf S, Zaidi A, Bhatti F, et al Outcome of isolated aortic valve replacement in patients with classic and paradoxic low-flow, low-gradient aortic stenosis. J Thorac Cardiovasc Surg. 2017; $154: 435-42$. 
3. Tribouilloy C, Lévy F, Rusinaru D, Guéret P, Petit-Eisenmann H, Baleynaud S, et al. Outcome after aortic valve replacement for low-flow/low-gradient aortic stenosis without contractile reserve on dobutamine stress echocardiography. J Am Coll Cardiol. 2009;53:1865-73.
4. Dayan V, Vignolo G, Magne J, Clavel MA, Mohty D, Pibarot P. Outcome and impact of aortic valve replacement in patients with preserved LVEF and low-gradient aortic stenosis. J Am Coll Cardiol. 2015;66:2594-603. 